J Psychosoc Nurs Ment Health Serv. 2013 October ; 51(10): 14-17. doi:10.3928/02793695-20130828-01.

\title{
Trouble Brewing:
}

\section{Pregaming Among High School and Incoming College Students}

\author{
Byron L. Zamboanga, PhD, Cara C. Tomaso, Amie L. Haas, PhD, Janine V. Olthuis, BA, \\ Sarah Borish, MEd, and Brian Borsari, PhD \\ Dr. Zamboanga is Associate Professor and Ms. Tomaso is undergraduate student, Smith \\ College, Northampton, Massachusetts; Dr. Haas is Associate Professor and Ms. Borish is \\ doctoral student, Pacific Graduate School of Psychology, Palo Alto University, Palo Alto, \\ California; Ms. Olthuis is doctoral candidate, Dalhousie University, Halifax, Nova Scotia, Canada; \\ and Dr. Borsari is Associate Professor (Research), Brown School of Public Health and Center for \\ Alcohol and Addiction Studies, Brown University, Providence, Rhode Island
}

\section{Abstract}

Pregaming (a.k.a., "prepartying," "pre-funking," or "predrinking") consists of drinking before going to a social function or gathering where alcohol may or may not be served. Existing research suggests that pregaming in high school and pre-college (i.e., the period between high school graduation and the start of college) is widespread. Moreover, pregaming prevalence appears to rapidly increase after students graduate from high school and transition into college. Thus, the purpose of this brief review is threefold: (a) to summarize the existing (albeit limited) research on pregaming among high school students and incoming college freshmen, (b) to present an overview of the risk factors that have been identified for participation in pregaming, and (c) to discuss the implications for practice that may be particularly relevant for school-employed/affiliated nurses as well as health practitioners who work in college settings.

Pregaming (a.k.a., "prepartying," "prefunking," or "predrinking") consists of drinking before going to a social function or gathering where alcohol may or may not be served (Borsari et al., 2007). Individuals pregame for a variety of reasons, which can include, but are not limited to, waiting for an event to start, a desire for rapid intoxication, anticipated alcohol access issues (e.g., due to cost reasons or limited availability), and/or safety reasons (e.g., greater awareness of the contents of one's drink). Although this behavior has been occurring for decades (formerly known as "anticipatory drinking," Straus \& Bacon, 1953, p. 113), only recently has pregaming become of interest due to its association with high-risk drinking, negative drinking outcomes (Barnett, Orchowski, Read, \& Kahler, 2013; Wahl, Sonntag, Roehrig, Kriston, \& Berner, 2013; Zamboanga et al., 2011), and increased quantity and frequency of regular drinking upon college entry (Haas, Smith, \& Kagan, 2013). Although the overwhelming majority of studies on pregaming have been conducted with students who have already entered college, this behavior is also an active part of many adolescents' drinking repertoire prior to beginning college (Haas, Smith, Kagan, \& Jacob, 2012; Kenney, Hummer, \& LaBrie, 2010; Zamboanga et al., 2011). As such, pregaming is often a problem "inherited" by colleges rather than "acquired" during college, thereby

\section{(c) SLACK Incorporated}

Address correspondence to Byron L. Zamboanga, PhD, Associate Professor, Smith College, 44 College Lane, Bass Hall, Northampton, MA 01063; bzamboan@ smith.edu.

The content is solely the responsibility of the author (B.B.) and does not necessarily represent the official views of the National Institute on Alcohol Abuse and Alcoholism or the National Institutes of Health. The remaining authors have no potential conflicts of interest, financial or otherwise. 
highlighting the need to understand the demographic and motivational roots of pregaming among high school students.

Existing research suggests that pregaming in high school and pre-college (i.e., the period between high school graduation and the start of college) is widespread (Table A, available in the online version of this article). In one study, $45 \%$ of college freshmen retrospectively reported pregaming during the last few months of high school (Kenney et al., 2010). Another cross-sectional study with high school students found that approximately $40 \%$ of students who drink also pregame (Zamboanga et al., 2011). Similarly, a large-scale crosssectional study with 9th and 10th grade German students found that $33 \%$ of the sample reported pregaming (Wahl et al., 2013).

Pregaming prevalence appears to rapidly increase upon high school graduation: $65 \%$ of entering college students who previously used alcohol pregamed in the 3 months between high school graduation and college entry (Haas et al., 2012), making the time between high school graduation and the start of college a high-risk transition period (Fromme, Corbin, \& Kruse, 2008; Sher \& Rutledge, 2007). Furthermore, pregaming has been shown to escalate as college-bound high school students settle into college life. Haas et al. (2013) sampled 708 incoming freshmen who reported prior alcohol use and found that $60 \%$ of them pregamed during the 3 months between the end of high school and the beginning of college; however, by 8 to 9 weeks into the semester, this percentage jumped to nearly $80 \%$. In another study, Barnett et al. (2013) reported pregaming prevalence rates of approximately $75 \%$ through the freshmen and sophomore years of college. Altogether, these studies suggest that pregaming is widespread among high school students and becomes increasingly prevalent as students transition and adjust to college life.

\section{WHO'S AT RISK?}

Although the research on pregaming among current high school students remains sparse, a few risk factors have been identified, including being male (Wahl et al., 2013; Zamboanga et al., 2011) and older (Zamboanga et al., 2011). Haas et al.'s (2012) study with incoming college freshmen also identified being male and Greek-affiliated (i.e., either rushing or pledging) as risk factors for pregaming prior to college entry. It is important to note, however, that a different pattern seems to emerge as college students settle into their freshmen year. Among college freshmen and sophomores, Barnett et al. (2013) found that women, ethnic minority students, and freshmen were more likely to pregame on days that they consumed alcohol compared to men, White students, and sophomores. However, men became more inebriated and sophomores consumed more alcohol on the days that they pregamed.

There are also a number of psychological factors associated with pregaming among high school and incoming college students, including the intention to get drunk, alcohol outcome expectancies (i.e., a person's anticipated effects of alcohol use), and personality factors. Drinking with the intention to get drunk is more common in high school students who pregame compared to their non-pregaming peers (Wahl et al., 2013). Zamboanga et al. (2011) did not find any associations between pregaming and general alcohol expectancies and drinking motives among high school students. However, greater positive alcohol expectancies have been linked to pregaming in both entering freshmen (Haas et al., 2012) and students who initiate pregaming upon college entry (Haas et al., 2013). Finally, fun seeking and goal directiveness personality tendencies were found to be associated with pregaming prior to college (Haas et al., 2013). Collectively, these studies suggest that there are psychological factors associated with students' risk for pregaming, some of which are more amenable to intervention (e.g., reducing positive expectancies via expectancy 
challenge procedures [Scott-Sheldon, Terry, Carey, Garey, \& Carey, 2012]) than others (e.g., fun seeking).

\section{WHAT EVENTS ARE ASSOCIATED WITH PREGAMING?}

Students pregame prior to many different types of events. For instance, in one study, a large proportion of high school student drinkers reported that they pregame for parties $(82 \%)$ and night sporting events (66\%), with some students also reporting pregaming for prom (24\%) and overnight school trips (6\%) (Zamboanga et al., 2011). Wahl et al.'s (2013) study with German 9th and 10th graders indicated that they pregamed before attending private parties (79\%); pubs, bars, and discotheques (77\%); concerts (36\%); the cinema (20\%); and sports events $(20 \%)$.

\section{PREGAMING AND NEGATIVE ALCOHOL-RELATED CONSEQUENCES}

Pregaming puts many high school and college students at risk for consuming large quantities of alcohol, as this behavior typically results in even more drinking at their next destination (Pedersen \& LaBrie, 2007). Not surprisingly then, negative alcohol-related consequences commonly occur as a product of pregaming (Barnett et al., 2013; Haas et al., 2012; Wahl et al., 2013; Zamboanga et al., 2011) and include problems that result from high blood alcohol concentrations (BACs), including blackouts, vomiting, and severe hangovers. Pregamers are also more likely to report getting into physical fights while drinking compared to nonpregamers (Barnett et al., 2013; Wahl et al., 2013). Retrospective reports have found that students who pregamed during the last few months of high school experienced more alcohol-related consequences (as indexed by the Alcohol Use Disorders Identification Test [Saunders, Aasland, Babor, de la Fuente, \& Grant, 1993)] in the first month of college than those who did not pregame (Kenney et al., 2010). In addition, high school students who pregame also participate frequently in other high-risk drinking activities (e.g., drinking games), thus elevating their potential risk for experiencing negative alcohol-related consequences (Zamboanga et al., 2011).

\section{IMPLICATIONS FOR PRACTICE}

The existing, although limited, research on pregaming behaviors among high school and incoming college students has a number of implications for practice. These implications may be particularly relevant for school-employed/affiliated nurses as well as health practitioners who work in college settings.

In our work with college and high school students, we have found that many students do not include drinks consumed during pregaming when asked to recollect/report how much they have consumed over the course of an evening. Therefore, health professionals who work with these student populations should assess not only quantity and frequency of overall drinking, but also specifically query pregaming consumption (e.g., "How many drinks do you consume while pregaming?"; "How often do you pregame?"; "Do you drink after you pregame?"). Research with college samples has shown that students reach substantially higher BACs at drinking events involving pregaming (Borsari et al., 2007).

Similarly, health professionals who administer alcohol screening measures should be aware of potential high-risk groups (i.e., males, older teens, and college students in general) and assess specific reasons for pregaming in these populations (Bachrach, Merrill, Bytschkow, \& Read, 2012; LaBrie, Hummer, Pedersen, Lac, \& Chithambo, 2012). Motives specific to pregaming have been found to be different from drinking motives in general and, when identified, may represent another point of intervention for health professionals. 
Information about pregaming prevalence, frequency, and associated alcohol consumption quantity could also be used to create brief, personalized, motivationally focused interventions that alert students to the risks associated with pregaming. These interventions may be particularly effective when an individual seeks medical attention after recently experiencing negative drinking consequences, as this represents a "teachable moment" when the individual may be more receptive to behavior change and where motivational interviewing methods may be easily employed.

Emerging research has indicated that simple, cost-effective interventions such as social norms campaigns can help reduce pregaming prevalence in entering freshmen (Haas \& Glider, 2013). Given the high prevalence of pregaming in high school and incoming college students, health care professionals who work with school districts and/or have influence on campus alcohol prevention programming may want to consider implementing these kinds of interventions on high school campuses as a way of reducing the prevalence and riskiness of this practice.

Given that a number of high school students pregame for parties and school-sponsored events (e.g., prom, sporting events), school nurses could work collaboratively with school personnel to establish environmental strategies that reduce risky pregaming behaviors or post-pregaming alcohol consumption. These strategies might include check points for intoxicated students that are going to prom, parties, or school-affiliated sports events (i.e., driving under the influence checkpoints at sporting events and proms; bike and foot patrols on school grounds; cooperation with local authorities to help monitor off-campus parties).

\section{CONCLUSION}

Research clearly demonstrates that (a) many high school students pregame prior to entering college; (b) pregaming is motivated by a number of reasons; and (c) this behavior is associated with many adverse effects. Health professionals who work with these populations should assess pregaming behaviors (occurrence, quantity/frequency, and motives) as part of their regular alcohol use screenings, as well as identify when pregaming may be a causative factor in an adolescent's experience of alcohol-related negative consequences. This information is invaluable on both the individual (i.e., working with specific patients) and community levels in coordinating and implementing the prevention and intervention efforts outlined in this review.

\section{Acknowledgments}

Ms. Olthuis received support from a Canadian Institutes of Health Research Vanier Graduate Scholarship; and Dr. Borsari received support from a National Institute on Alcohol Abuse and Alcoholism grant (R01 AA017427).

\section{References}

Bachrach RL, Merrill JE, Bytschkow KM, Read JP. Development and initial validation of a measure of motives for pregaming in college students. Addictive Behaviors. 2012; 37:1038-1045.10.1016/ j.addbeh.2012.04.013 [PubMed: 22591951]

Barnett NP, Orchowski LM, Read JP, Kahler CW. Predictors and consequences of pregaming using day- and week-level measurements. Psychology of Addictive Behaviors. 2013 Advance online publication. 10.1037/a0031402

Borsari B, Boyle KE, Hustad JTP, Barnett NP, O’Leary Tevyaw T, Kahler CW. Drinking before drinking: Pregaming and drinking games in mandated students. Addictive Behaviors. 2007; 32:2694-2705.10.1016/j.addbeh.2007.05.003 [PubMed: 17574344]

Fromme K, Corbin WR, Kruse MI. Behavioral risks during the transition from high school to college. Developmental Psychology. 2008; 44:1497-1504.10.1037/a0012614 [PubMed: 18793080] 
Haas, AL.; Glider, P. Evaluating the efficacy of a multi-component targeted pregaming intervention for entering college students. 2013. Manuscript submitted for publication

Haas AL, Smith SK, Kagan K. Getting "game": Pregaming changes during the first weeks of college. Journal of American College Health. 2013; 61:95-105.10.1080/07448481.2012.753892 [PubMed: 23409859]

Haas AL, Smith SK, Kagan K, Jacob T. Pre-college pregaming: Practices, risk factors, and relationship to other indices of problematic drinking during the transition from high school to college. Psychology of Addictive Behavior. 2012; 26:931-938.10.1037/a0029765

Hustad JTP, Mastroleo NR, Urwin R, Zeman S, LaSalle L, Borsari B. Tailgating and pregaming by college students with alcohol offenses: Patterns of alcohol use and beliefs. Substance Use and Misuse. (in press).

Kenney SR, Hummer JF, LaBrie JW. An examination of prepartying and drinking game playing during high school and their impact on alcohol-related risk upon entrance into college. Journal of Youth and Adolescence. 2010; 39:999-1011.10.1007/s10964-009-9473-1 [PubMed: 19904593]

LaBrie JW, Hummer JF, Pedersen ER, Lac A, Chithambo T. Measuring college students' motives behind prepartying drinking: Development and validation of the prepartying motivations inventory. Addictive Behaviors. 2012; 37:962-969.10.1016/j.add-beh.2012.04.003 [PubMed: 22564754]

Pedersen ER, LaBrie JW. Partying before the party: Examining prepartying behavior among college students. Journal of American College Health. 2007; 56:237-245.10.3200/JACH.56.3.237-246 [PubMed: 18089504]

Saunders JB, Aasland OG, Babor TF, de la Fuente JR, Grant M. Development of the alcohol use disorders identification test (AUDIT): WHO collaborative project on early detection of persons with harmful alcohol consumption. II. Addiction. 1993; 88:791-804.10.1111/j. 1360-0443.1993.tb02093.x [PubMed: 8329970]

Scott-Sheldon LAJ, Terry DL, Carey KB, Garey L, Carey MP. Efficacy of expectancy challenge interventions to reduced college student drinking: A meta-analytic review. Psychology of Addictive Behaviors. 2012; 26:393-405.10.1037/a0027565 [PubMed: 22428862]

Sher KJ, Rutledge PC. Heavy drinking across the transition to college: Predicting first-semester heavy drinking from precollege variables. Addictive Behaviors. 2007; 32:819-835.10.1016/j.addbeh. 2006.06.024 [PubMed: 16860940]

Straus, R.; Bacon, SD. Drinking in college. New Haven, CT: Yale University Press; 1953.

Wahl S, Sonntag T, Roehrig J, Kriston L, Berner MM. Characteristics of predrinking and associated risks: A survey in a sample of German high school students. International Journal of Public Health. 2013; 58:197-205.10.1007/s00038-012-0409-2 [PubMed: 23007874]

Wiers RW, Kummeling RHC. An experimental test of an alcohol expectancy challenge in mixed gender groups of young heavy drinkers. Addictive Behaviors. 2004; 29:215-220.10.1016/ S0306-4603(03)00081-9 [PubMed: 14667432]

Wiesler E, Wahl S, Lucius-Hoene G, Berner M. "We're not getting wasted beforehand, we're just drinking a few beers." "Pregaming": A current practice in adolescent alcohol consumption. Forum: Qualitative Social Research. 2013; 14:1-32.

Zamboanga BL, Borsari B, Ham LS, Olthuis JV, Van Tyne K, Casner HG. Pregaming in high school students: Relevance to risky drinking practices, alcohol cognitions, and the social drinking context. Psychology of Addictive Behaviors. 2011; 25:340-345.10.1037/a0022252 [PubMed: 21443300] 
Table A

Summary of Studies Examining Pregaming among High School Students and Incoming College Students

\begin{tabular}{|c|c|c|}
\hline \multicolumn{3}{|c|}{ Studies Conducted with Current High School } \\
\hline Citation & $\begin{array}{l}\text { Sample Description and } \\
\text { Prevalence }\end{array}$ & $\begin{array}{l}\text { Method of Assessing Pregaming } \\
\text { Behavior }\end{array}$ \\
\hline $\begin{array}{l}\text { Zamboanga, } \\
\text { Borsari, Ham, } \\
\text { Olthuis, Van } \\
\text { Tyne, \& } \\
\text { Casner (2011) }\end{array}$ & 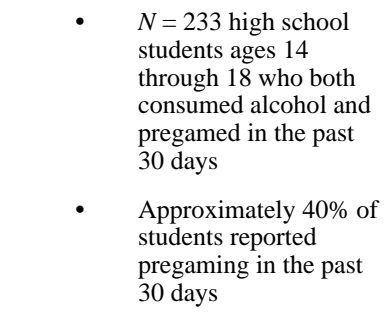 & $\begin{array}{l}\text { - Students reported } \\
\text { how many times they } \\
\text { pregamed on a } 6- \\
\text { point scale over the } \\
\text { past month }(1=\text { one } \\
\text { time ... } 6=\text { six times } \\
\text { or more })\end{array}$ \\
\hline $\begin{array}{l}\text { Wahl, } \\
\text { Sonntag, } \\
\text { Roehrig, } \\
\text { Kriston, \& } \\
\text { Berner (2012) }\end{array}$ & $\begin{array}{l}N=7579^{\text {th }} \text { and } 10^{\text {th }} \\
\text { grade German students } \\
(\sim 1 / 3 \text { of the sample } \\
\text { reported predrinking, } \\
\text { and of these } \\
\text { predrinkers, } \sim 1 / 3 \\
\text { reported predrinking } \\
\text { rarely, } \sim 1 / 3 \text { reported } \\
\text { predrinking } \\
\text { occasionally, and } \sim 1 / 3 \\
\text { reported predrinking }\end{array}$ & $\begin{array}{l}\text { - Students who said } \\
\text { they sometimes drank } \\
\text { were asked, "Do you } \\
\text { normally drink } \\
\text { alcohol before going } \\
\text { out?" and selected } \\
\text { one of the following } \\
\text { options: hardly ever, } \\
\text { seldom, sometimes, } \\
\text { often, or (almost) } \\
\text { always. }\end{array}$ \\
\hline
\end{tabular}

Weisler, Wahl,

Lucius-Hoene,

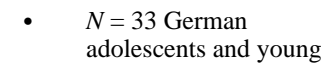

- $\quad$ Participants were divided into eight discussion groups which lasted between 10-30 minutes. Adolescents were asked about their attitudes toward public alcohol consumption and a typical evening of

\section{Key Findings}

- $\quad$ Being older, reporting high levels of hazardous alcohol use, and high frequency of drinking games participation predicted higher odds of reporting pregaming behaviors.

- $\quad$ Those who pregamed frequently were more likely to be male and also reported higher levels of hazardous alcohol use than those who pregamed less frequently.

- $\quad$ A high proportion of pregamers reported pregaming before parties and sporting events.

- $\quad$ Boys were more likely to pregame than girls.

- $\quad$ Proportion trends suggest that a higher percentage of $9^{\text {th }}$ graders compared to $10^{\text {th }}$ were predrinkers.

- $\quad$ Frequent predrinkers (i.e., reported predrinking often or always) were more likely to report hazardous alcohol use and experience more negative drinking consequences (e.g., frequent fights and alcohol-induced blackouts) than non-predrinkers.

- $\quad$ Predrinkers stated more often than non-predrinkers that they drank with the intention of getting drunk.

- $\quad 84.9 \%$ of predrinkers reported predrinking at home, $78.7 \%$ of predrinkers reported predrinking before attending private events, and $77.2 \%$ reported predrinking before going to bars or pubs.

- $\quad$ Participants described what a typical evening of pregaming would look like, including how they locate convenient places to drink, how they procure alcohol and what types of drinks they typically have, and how pregaming fits into the chronology of the rest of the evening.

- $\quad$ Each group had its own pregaming ritual; control (e.g., learning one's limits with respect to alcohol consumption, escaping parental monitoring) and the ability to deal with age-specific challenges emerged as two major themes of the discussions.

- $\quad$ Participants identified wanting to save money, celebration of group cohesion, and reducing or eliminating 


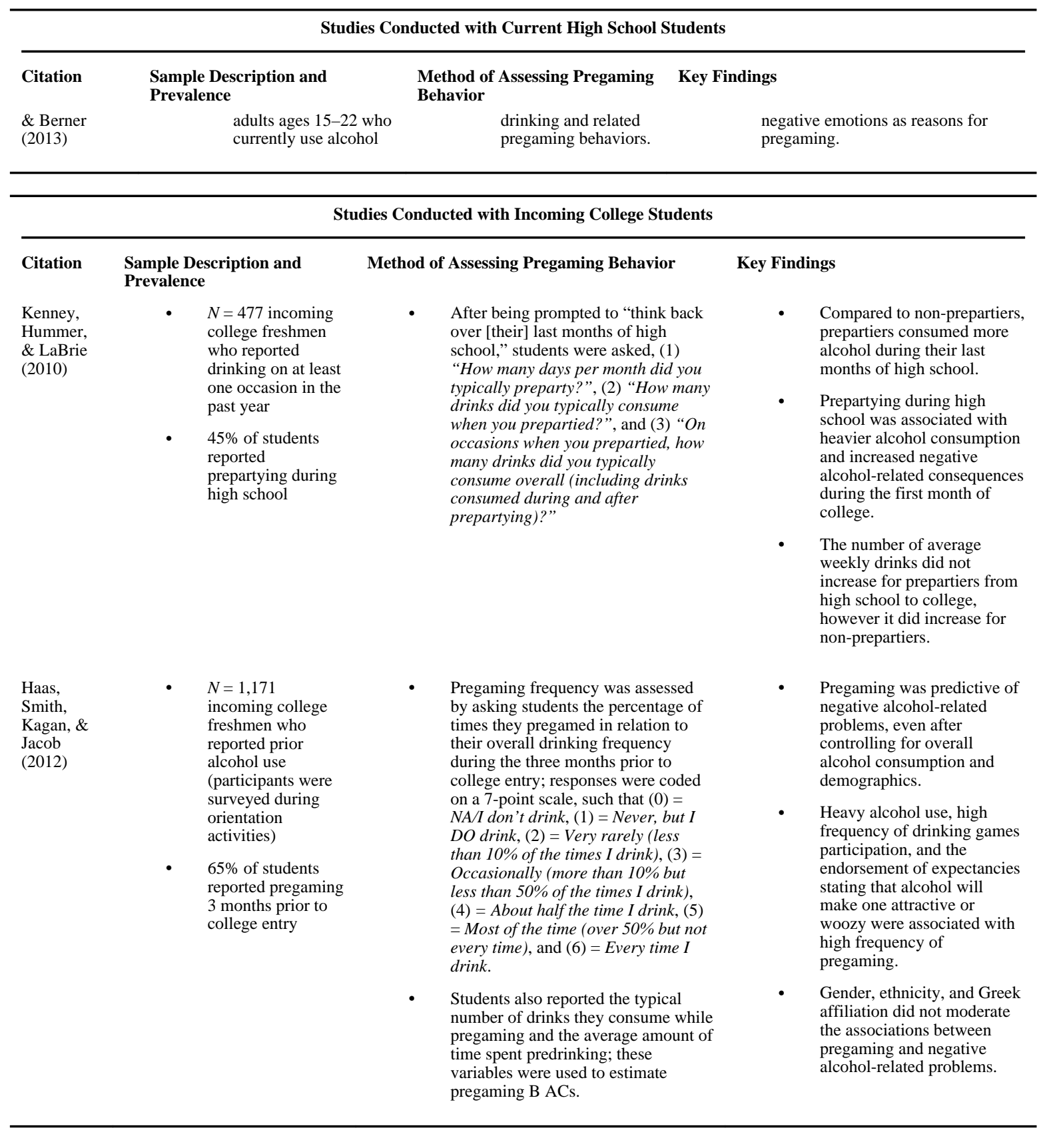

Studies Conducted with Current College Freshmen and Sophomores

\begin{tabular}{|c|c|c|c|}
\hline Citation & $\begin{array}{l}\text { Sample Description and } \\
\text { Prevalence }\end{array}$ & $\begin{array}{l}\text { Method of Assessing Pregaming } \\
\text { Behavior }\end{array}$ & Key Findings \\
\hline $\begin{array}{l}\text { Haas, Kagan, } \\
\text { \& Smith } \\
(2013)\end{array}$ & $\begin{array}{l}N=708 \text { incoming } \\
\text { college freshmen } \\
\text { who reported } \\
\text { alcohol use } \\
\text { (measured during } \\
\text { orientation and then } \\
8-9 \text { weeks after the }\end{array}$ & $\begin{array}{l}\text { Pregaming frequency was } \\
\text { assessed by asking students } \\
\text { the percentage of times they } \\
\text { pregamed in relation to their } \\
\text { overall drinking frequency } \\
\text { during the past summer and } \\
\text { during the fall semester; } \\
\text { responses were coded on a 7- } \\
\text { point scale, such that }(0)=\end{array}$ & $\begin{array}{l}\text { - Not only was there an } \\
\text { approximate } 20 \% \text { increase in } \\
\text { pregaming prevalence over the } \\
\text { first } 8 \text { to } 9 \text { weeks of college, but } \\
\text { students also consumed more } \\
\text { drinks (and therefore reached } \\
\text { higher BACs) per pregaming } \\
\text { occasion after the first several } \\
\text { weeks of college. }\end{array}$ \\
\hline
\end{tabular}


Studies Conducted with Current College Freshmen and Sophomores

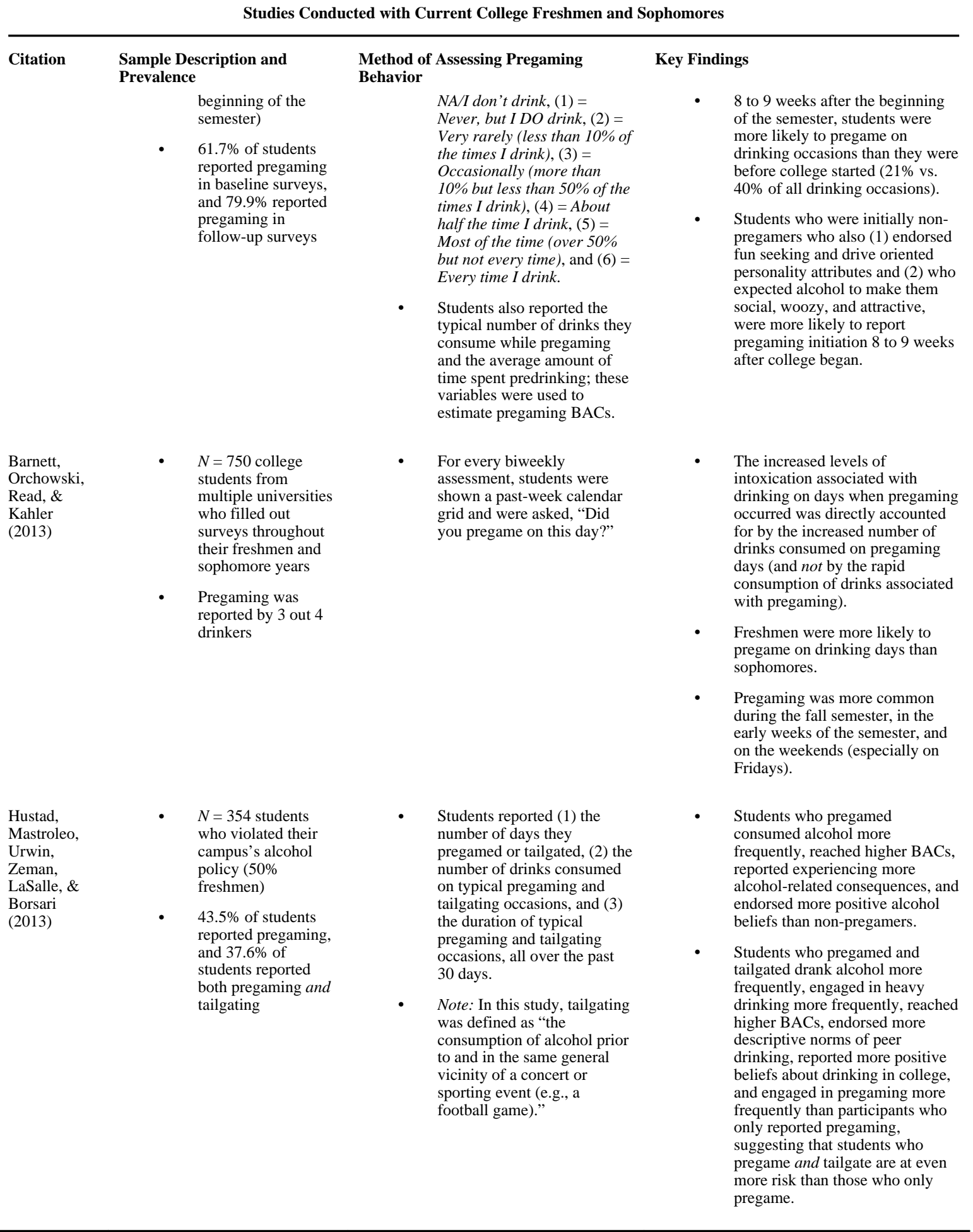

